\title{
CONSTITUINDO A CONSTITUIÇÃO: ENTRE PARADOXOS, RAZÕES E RESULTADOS
}

\author{
Bruno Meneses Lorenzetto e Katya Kozicki
}

CONSTITUTING THE CONSTITUTION: PARADOXES, REASONS AND RESULTS

\section{RESUMO}

O ARTIGO TEM COMO OBJETIVO A IDENTIFICAÇÃO DE PARADOXOS NOS MOMENTOS CONSTITUINTES, MAS TAMBÉM NA CONTINUIDADE DA TENSÃO ENTRE CONSTITUCIONALISMO E DEMOCRACIA. TAIS PARADOXOS AUXILIAM NA COMPREENSÃO DE PROBLEMAS NA JURISDIÇÃO CONSTITUCIONAL E NOS PROCESSOS DE PRODUÇĀO DA CONSTITUICCÃO. ELES TAMBÉM SÃO IDENTIFICADOS NAS CRÍTICAS À AGREGAÇÃO DE RESULTADOS NAS FORMULAÇŌES DE DECISŌES COLETIVAS. NO QUE DIZ RESPEITO À REALIDADE BRASILEIRA, ANALISA-SE A APROXIMAÇĀO DE NOSSA TRADIC̣ÃO JURÍDICA A ELEMENTOS ESTRUTURANTES DO COMMON LAW, ASSIM COMO DISCUTE-SE A NĀO TRANSCENDÊNCIA DOS MOTIVOS DETERMINANTES NAS DECISÕES PROFERIDAS PELO SUPREMO TRIBUNAL FEDERAL.

\section{PALAVRAS-CHAVE}

JURISDIÇÃO CONSTITUCIONAL; CONSTITUCIONALISMO; DEMOCRACIA; RATIO DECIDENDI.

\begin{abstract}
THE ARTICLE HAS AS ITS OBJECTIVE THE IDENTIFICATION OF PARADOXES ON CONSTITUENT MOMENTS, BUT ALSO ON THE CONTINUITY OF THE TENSION BETWEEN CONSTITUTIONALISM AND DEMOCRACY. THOSE PARADOXES HELP ON THE COMPREHENSION OF THE PROBLEMS RELATED TO THE CONSTITUTIONAL JURISDICTION AND ON THE PROCESSES OF CONSTITUTION MAKING. THEY ARE ALSO IDENTIFIED ON THE CRITIQUES DIRECTED TO THE AGGREGATION OF RESULTS ON THE FORMULATION OF COLLECTIVE DECISIONS. IN REGARD OF BRAZILIAN REALITY, IT IS ANALYSED THE APPROXIMATION OF OUR JURIDICAL TRADITION TO STRUCTURAL ELEMENTS OF THE COMMON LAW, AS WELL AS IT IS DISCUSSED THE NONTRANSCENDENCE OF THE DETERMINANT REASONS ON THE DECISIONS MADE BY THE SUPREMO TRIBUNAL FEDERAL.
\end{abstract}

\section{KEYWORDS}

CONSTITUTIONAL JURISDICTION; CONSTITUTIONALISM; DEMOCRACY; RATIO DECIDENDI.

\section{INTRODUÇÃO}

O problema da inicialização (bootstrapping), ${ }^{1}$ do início de um processo autorreferenciado independente de fatores externos, do "fundador" e seus similares, reporta a modos solipsistas de produzir justificações políticas e jurídicas. Tais estruturas argumentativas, que podem ser identificadas com maior nitidez em momentos constituintes, 
nos quais ocorre uma verdadeira ruptura com as autoridades autorizadoras, encontram ao menos uma herança na prática jurisdicional, que é o manejo endógeno por parte da magistratura de justificativas na construção de decisões jurídicas. A prática autorreferenciada, quando realizada em conjunturas inaugurais, nos casos de formação de um novo ordenamento jurídico, não é tratada como um problema, ao contrário, faz-se necessária para sustentar o conjunto de normas que irão regular a comunidade política. Todavia, nos instantes de estabilização e produção contínua da jurisdição constitucional tal prática precisa ser questionada.

Uma das origens do problema da autorreferência das decisões pode ser identificada em modos de articulação entre constitucionalismo e democracia que levam à compreensão de um paradoxo subjacente em tal relação. ${ }^{3}$ Se, de um lado, a tensão derivada da relação entre constitucionalismo e democracia é fundamental para a atualização da relação entre o mundo fático e o conjunto normativo, por outro lado, possui uma faceta negativa que é dimanada de teorias que procuram elevar os magistrados à condição de senhores absolutos da lei, com liberdade para produzir o direito em casos concretos.

O fio condutor do presente artigo está na identificação de tais paradoxos, tanto nos momentos constituintes como na continuidade da tensão entre constitucionalismo e democracia, o que permite o diagnóstico de dificuldades na jurisdição constitucional e nos processos de produção da Constituição advindos de sua gênese. Diante do entendimento de que a tarefa de produzir a Constituição se estende para além de seu ponto de partida e de que as Cortes Constitucionais passaram a ter papel de destaque como mediadoras de tal função, não é demasiado afirmar que se continua a produzir a Constituição por outros meios no momento em que os Poderes estão constituídos. Além disso, pode-se identificar um conjunto teórico que mimetiza o problema da autorreferência existente na origem, porém em cenários constituídos, e não constituintes.

No caso do Brasil, um dos temas que enfrenta tais dificuldades diz respeito à transcendência dos motivos determinantes nas decisões proferidas pelo Supremo Tribunal Federal (STF). ${ }^{4}$ A doutrina da transcendência dos motivos determinantes das decisões procura fazer com que a eficácia dos julgados transcenda os casos singulares e possa vir a ser adotada na fundamentação de outros casos. A força vinculante da decisão não pode ser limitada, por isso, à parte dispositiva da decisão - estende-se aos fundamentos determinantes do julgado que o STF venha a proferir na realização do controle abstrato de constitucionalidade. Os fundamentos que consubstanciam as razões de decidir, ratio decidendi, têm o condão de vincular o Judiciário e também a Administração Pública. Da mesma forma que ocorre em Assembleias Constituintes, a não observância da ratio decidendi promove o duplo risco do recurso a argumentos autorreferenciados e do eclipsar das razões em favor dos resultados, porém em um cenário de Poderes estabilizados. ${ }^{5}$ 
O atual manejo de certas decisões proferidas pelo STF indica que a desconsideração das razões, com a diminuição ou desprezo da força normativa dos motivos determinantes, leva a um empobrecimento da jurisdição constitucional e se aproxima de um arriscado sistema binário de definição de resultados pela Corte. Isso só pode ser realizado quando o Poder acredita ter acesso - ainda que limitado - ao espaço vazio de poder, ao momento de inauguração da comunidade política, mesmo que isso não venha a ser respaldado por elementos de soberania popular.

Partindo-se do reconhecimento de que o Brasil vivencia um conjunto de reestruturações no Judiciário que indicam uma aproximação de nossa tradição jurídica a elementos estruturantes do Common Law, a necessidade de considerar as razões antes dos resultados não é apenas um meio de inibir paradoxos, mas também uma forma de restringir o solipsismo de certas decisões e recordar que a fundamentação não é um elemento acessório da decisão, mas seu cerne constitutivo. Além disso, é uma maneira de tornar os magistrados responsáveis, não necessariamente diante do povo, mas, certamente, perante suas próprias razões.

A metodologia empregada para a confecção do artigo pautou-se na investigação de documentos doutrinários, de precedentes e de normas. Tais elementos serviram de suporte para as considerações formuladas sobre o tema investigado.

\section{FundaçÃo}

Perante o desenvolvimento de novas reflexões para a questão da fundação da ordem civil, bem como diante das crises na autoridade religiosa presentes na Reforma Protestante, no século XVI se fez possível esboçar os primeiros sinais de uma redefinição entre a política e a religião. No século XIX a presença dos significados religiosos ainda era determinante para averiguar as transformações políticas da sociedade. Entretanto, com o advento do século XX a fundação teológico-política das sociedades passou a ser negada de maneira mais contundente (LEFORT, 2006, p. 148).

Para Claude Lefort, a permanência do teológico-político não seria necessária se a democracia fosse capaz de se separar do passado. Por isso, o político - o lugar que o novo procura ocupar na modernidade - ainda carrega estruturas teológicas antigas. Assim, um dos principais elementos que o teológico e o político compartilham é a capacidade de fazer com que as pessoas consintam perante um regime, eles determinam a maneira do (dever) ser em sociedade. Por isso, a forma simbólica compartilhada pela pré-modernidade e a modernidade está justamente em suas respectivas capacidades de instituir, conferir um significado para a identidade social. ${ }^{6}$

O político refere-se à produção, à genealogia da sociedade, às diferentes formas em que a comunidade política se apresenta, abarca o modo de instituição da vida em sociedade, a organização do governo, a configuração dos espaços e do tempo (LORENZETTO, 2013). Em decorrência disso, a importância reflexiva do passado está no modo 
como este é observado, internalizado, quais suas imagens presentes e, além disso, como ele produz aquilo que é definido como próprio da comunidade política (seus pactos, suas promessas).

A observação da existência de um "espaço vazio" no âmbito político, apresentada por Lefort, decorreu da constatação de uma série de dilemas a propósito da referência inicial de categorias centrais para a modernidade, como o Povo, o Estado e a Nação (LEFORT, 1991). Nos tempos modernos, o fenômeno da secularização impossibilitou o recurso à autoridade religiosa para a fundamentação dos poderes. Desse modo, a fundamentação foi deslocada de um espaço teórico para o seu exercício prático.

O "vazio de poder" não se estabeleceu na ausência de pessoas que viessem a almejar sua ocupação, mas pela existência de uma quantidade ilimitada daqueles que o pleiteavam, das inúmeras vozes que afirmavam ser detentoras do poder constituinte. Nesse cenário, a legitimidade precisou ser formulada em nome do povo, e o problema de quem são os devidos representantes do povo se tornou parcialmente indeterminado. Entende-se, contemporaneamente, que uma das funções do poder constituinte é a de manter tal problema em aberto, ou seja, permitir que inúmeras vozes pleiteiem a ocupação desse espaço de poder, não apenas pela ameaça da transformação do povo em argumento legitimador de práticas desconectadas com os representados, mas também pelo distanciamento entre representantes e representados. ${ }^{7}$

Trata-se, por isso, de um problema político clássico, o qual está refletido no desenvolvimento de formas de governo que tenham o condão de posicionar o direito acima dos homens ou, em outros termos, direcionar a (boa) lei para a formação de (boas) pessoas, cidadãos. Jean-Jacques Rousseau entendia que boas leis produziam bons cidadãos, mas também propugnava que boas leis apenas poderiam ser produzidas por bons cidadãos que, para serem legitimados, precisavam se reunir em assembleia. ${ }^{8} \mathrm{Tal}$ disposição gerava a dificuldade no sentido de que os cidadãos, reunidos em assembleia para formar um novo Estado, não teriam as qualidades morais necessárias para produzir boas leis, uma vez que eles haviam sido formados por instituições injustas. Por causa disso, Rousseau atribuiu ao legislador a função privilegiada de inspirar os novos cidadãos na produção de uma identidade coletiva, a qual permitiria que eles e seus descendentes fossem transformados em bons cidadãos. ${ }^{9}$

O referido paradoxo proposto por Rousseau enfrenta a circularidade argumentativa similar ao questionamento apresentado por Sieyès (1997): de onde advém a autoridade daqueles que se reúnem para constituir um novo governo? Uma vez que tais pessoas não são, ainda, cidadãos, não estão autorizadas para fazer aquilo que almejam - criar uma nova comunidade política, uma nova fonte de autorizações. A impossibilidade do recurso aos argumentos próprios da teologia política é percebida como uma das fontes do paradoxo.

No momento da formação de uma assembleia constituinte, na realização de grandes mudanças estruturais que venham a redimensionar a disposição das instituições e 
da relação entre os poderes, em eventos de alta intensidade política, os questionamentos são (re)apresentados, ainda que em formas não tão diretas. Por isso, questiona-se, por exemplo, qual a origem da autoridade, da permissão, do poder para produzir um conjunto de leis que venham a redefinir o sentido de pertencimento à comunidade e os limites e funções das instituições públicas? Tais interrogações, habitualmente, não são invocadas no momento de produção da legislação ordinária, mas sim em instantes políticos constituintes, em momentos de criação de um novo Estado ou em casos de distensão entre os poderes. O paradoxo se estabelece ao colocar as leis acima dos homens e condicionar a validade das leis que eles estão promulgando a alguma fonte superior de autoridade.

A identificação do paradoxo não impede que decisões políticas substantivas venham a ser tomadas, mesmo em arenas onde a legitimação das decisões não possua adesão significativa dos outros agentes políticos ou dos representados. Aquilo que acaba por suceder é a tomada da decisão política e a busca pela formação da legitimidade através do conjunto de poderes constituídos. Uma vez que as Repúblicas não estão fundadas em apenas um momento histórico isolado, mas em uma progressiva discussão entre seus cidadãos, que moldam, ao longo dos anos, as identidades e diferenças que os constituem civicamente, a preservação e a emenda da fundação acabam por atribuir robustez política para a comunidade política (HOLMES, 1995).

\section{OS PARADOXos do DIREITO E DA POLÍTICA}

O paradoxo da política é um dos problemas mais importantes da democracia, qual seja: como fazer o Poder pertencer ao povo? O problema está no fato de que o povo, na forma de multidão, não está habilitado para tomar todas as decisões importantes que a arena pública demanda (ROUSSEAU, 1923). Lida-se com o dilema de transformar a massa amorfa de uma multidão em um povo de um país. ${ }^{10}$ Segundo Bonnie Honig, o paradoxo da política enfatiza a circularidade entre os autores e os sujeitos da lei, criaturas e criadores de direitos (HONIG, 2009, p. 3). O paradoxo, ao mesmo tempo que evidencia os limites do direito, demanda que nos tornemos responsáveis pelas leis, pela possibilidade da continuidade do conjunto de instituições que conformam a tessitura política.

Observa-se, portanto, que a invocação da categoria povo se conecta com a necessidade de legitimação ou, no mesmo sentido, de fundamento. Ralph Christensen afirma, nesse sentido, que:

O povo igualmente aparece na teoria jurídica da democracia enquanto bloco. Ele é a pedra fundamental imóvel da teoria da soberania popular e fornece como lugar-comum de retórica a justificativa para qualquer ação do Estado. Nessa utilização em bloco o conceito de povo justamente encobre 
as diferenças que permitiriam distinguir entre retórica ideológica e democracia efetiva. (CHRISTENSEN, 1998, p. 35)

Não apenas isso, a utilização do conceito em questão - em nome do povo, soberania popular, a supremacia do interesse público - no campo jurídico ou político serve como forma de solapar as origens, os fundamentos, as fundações dos Estados, dos direitos e da própria representação política.

A "rachadura" constante nas teorias da soberania popular se expõe nos casos em que ocorre a conexão entre "povo" e "dominação" para a definição da democracia. A diferença entre os conceitos, contudo, é a de que o povo, observado como totalidade isolada, é amorfo e dele não é possível deduzir uma vontade. Aquilo que se faz possível extrair das estruturas de dominação é a formação de uma vontade particular, simbolizada pelos representantes políticos.

A alternativa para a lógica da dominação é a abertura para o processo contínuo de refundação e do estabelecimento da legitimidade a partir das diferenças. Christensen lembra que: "A distinção impura entre instituição e preservação da democracia já pode ser observada no seu começo, quando os revolucionários democráticos invocam um povo que ainda está por ser criado” (CHRISTENSEN, 1998, p. 40). Por isso, a interação entre o instituído e o instituinte conduz para um outro olhar perante a democracia, em que sua reprodução e fundamentação não encontram um fim, sem se autoatribuir a totalidade da vontade popular.

O paradoxo da política não se limita ao problema da fundação - de um povo, de um Estado, de uma instituição política - pois se torna uma indagação que é formulada na prática política cotidiana, em que os cidadãos precisam definir, através de disputas democráticas, qual é a vontade geral que irá guiar suas políticas públicas.

O paradoxo da política, em tais moldes, não pode ser solucionado pelo direito ou por instituições jurídicas, nem mesmo pode ser domesticado por normas universais ou cosmopolitas (HONIG, 2009, p. 3). Contudo, ao se refletir sobre a complexidade social que perpassa as atuais relações sociais, percebe-se que ao direito são atribuídas muitas outras tarefas que vão além da simples função de estabilização. ${ }^{11} \mathrm{O}$ exercício da soberania popular se realiza nessa clivagem, entre a indeterminação do momento político presente e a abertura para o novo.

Outra maneira aventada para solucionar o paradoxo da política é o recurso ao constitucionalismo. Os limites impostos por uma Constituição reduzem os danos que uma multidão amorfa pode vir a causar, como a episódica supressão de direitos e garantias fundamentais motivada por paixões ou por agendas fundamentalistas (a supressão da liberdade religiosa em nome de uma religião majoritária). Em tais circunstâncias, a tensão que se desenvolve não é mais entre a soberania popular e a vontade geral do povo, mas entre a democracia e o constitucionalismo.

O cerne dessa tensão está no controle de constitucionalidade. A ideia, apresentada 
em um primeiro plano, é incômoda: pois como o governo pode explicar ou justificar uma prática aparentemente não democrática por parte do Judiciário em que produções populares e democráticas (leis) são submetidas a um "teste" de juridicidade por meio de uma lei superior (Constituição)? A busca por harmonizar os dois lados envolve polos que acabam por se encontrar radicalmente comprometidos: a defesa do ideal de um governo limitado por normas (constitucionalismo) e o ideal de um governo exercido pelo povo (democracia). ${ }^{12}$

Nos moldes primários da dicotomia, a democracia se apresenta como o espaço do autogoverno, o povo de um país que toma decisões substantivas sobre as formas e os conteúdos que definem seu espaço compartilhado intersubjetivamente, sua comunidade, o mesmo povo que decide (autonomamente) as regras que definem sua associação política. O constitucionalismo se expõe, por sua vez, como o meio previamente estabelecido por uma norma superior pelo qual são realizados processos de tomada de decisão coletiva. A Constituição é a lei que define o processo legislativo (law of lawmaking), controla o processo de produção legislativa, as leis que venham a ser integradas no ordenamento jurídico, definindo os atores legitimados para sua produção e os seus procedimentos. Frank Michelman aduz que também faz parte do constitucionalismo o entendimento de que as leis fundamentais (ou uma parcela delas) são intocáveis por políticas majoritárias (MICHELMAN, 1999, p. 6).

No que tange à democracia, observa-se ao menos duas grandes variações: a primeira apresenta-se como um problema do povo que já dispõe de direitos específicos, a perspectiva substancialista; a segunda variação, procedimentalista, trata a democracia como uma questão dos procedimentos usados para decidir quais direitos as pessoas devem possuir. ${ }^{13}$

Michelman entende que as duas variações estão preocupadas em lidar com o problema rousseauniano de encontrar uma forma de associação política, definir arranjos institucionais para a produção legislativa em que cada indivíduo mantém seu autogoverno, resguarda sua própria capacidade de decidir as direções éticas de sua vida, tem a possibilidade de definir e regular essas escolhas substantivas (ROUSSEAU, 1923).

Isso também pode ser observado como meio para a promoção do autogoverno, em que cada indivíduo manifesta suas razões e, eventualmente, desenvolve identificações com as vontades políticas ou com as leis, assim como outros atos derivados de atividades coletivas, tratando tais atos como “próprios”. Desse modo, o indivíduo sai de sua relação puramente solipsística, se identifica reflexivamente com os atos externos do mundo compartilhado com a pluralidade de pessoas e trata a atividade como "sua".

Deve-se considerar que as instituições são criações sociais e que a produção legislativa acaba por incorporar manifestações de diversos grupos que compõem a sociedade - em países que respeitem a democracia e a pluralidade. Ademais, a própria definição de democracia pressupõe, em termos mínimos, que discussões sejam realizadas e que estas sejam instrumentalizadas em forma de votações, nas quais todos 
possam participar em iguais condições formais. Assim, aqueles que preenchem os requisitos para serem considerados cidadãos da comunidade política podem se habilitar para exercer seu direito de votar e ser votado, de decidir questões substantivas da coletividade.

Dá-se mais um passo no sentido da compreensão de que não é apenas a artificialidade do processo representativo que demanda atenção, mas também a artificialidade da legislação com pretensão de universalidade. Ou seja, o respeito ao limite fático quando se constrói um ordenamento normativo, o qual é tratado como o espelho da vontade de uma coletividade. Tal espelho não pode ser abrangente o suficiente para refletir a vontade individual de, por exemplo, oito milhões de pessoas que moram em uma cidade. Por isso, a construção legislativa acaba por utilizar termos abstratos e generalizantes e suas razões tendem a responder às demandas da vontade geral e não ao agregado que caracteriza a vontade de todos (ROUSSEAU, 1923).

Para Dworkin, a definição de democracia pressupõe valores substantivos " a priori”, de acordo com os direitos que um país define como fundamentais, que podem conter ou não fins e valores democráticos (DWORKIN, 1985). Alguns critérios precisam ser observados: o afastamento da noção de castas sociais, a garantia de direitos políticos amplos e iguais, a prevenção de discriminações arbitrárias e do uso opressivo do poder do Estado (direitos negativos), e, ainda, a garantia das liberdades de pensamento, expressão e associação, bem como da independência moral e intelectual de cada cidadão.

Para Dworkin, entregar ao judiciário a autoridade "final" para definir o sentido de cláusulas constitucionais de forma mais concreta não leva necessariamente a um arranjo antidemocrático. Pois a democracia estaria garantida em seus níveis elementares nos textos normativos e, uma vez que existe um compromisso com a democracia, este não pode ser sustentado apenas por meio de princípios abstratos, eles precisam ser concretizados através de interpretações de acordo com o conjunto normativo previamente estabelecido. Outro aspecto que acaba por ser referenciado é a possibilidade de o povo decidir, através de mecanismos democráticos, todas as questões políticas que emergem na comunidade. ${ }^{14}$ Existe um amplo espectro de questões que não apenas podem, mas devem ser submetidas aos processos democráticos de decisão pelo povo, através de manifestações diretas ou por meio de seus representantes.

Contudo, o problema não está nesse espaço, mas no núcleo duro do sistema normativo, na possibilidade da decisão sobre os direitos fundamentais, aqueles mesmos que habilitam a arquitetura da comunidade política que busca conciliar a existência de um conjunto de normas com a democracia. Ou seja, a possibilidade de uma decisão sobre o desenho institucional da comunidade política, que resguarda valores substantivos ao impor limites à atuação do governo, como a distribuição de competências e funções e através de um rol de direitos fundamentais, dentre os quais está elencada a própria democracia. 
A perspectiva de Dworkin sobre a democracia leva à exclusão das leis fundamentais do domínio dos procedimentos democráticos, elas não se submetem aos processos deliberativos regulares existentes na comunidade (DWORKIN, 1985). Deve-se lembrar que, no momento da aplicação da norma aos casos concretos, sempre existirá algum grau de interpretação dos signos linguísticos disponíveis na gramática normativa e a construção constitucional será o produto da hermenêutica de cláusulas constitucionais, de precedentes e da doutrina. Por isso, Dworkin defende a leitura moral das cláusulas centrais da Constituição que garantem direitos que se apresentam de forma abstrata. ${ }^{15}$

A teoria da leitura moral sofre, porém, com o seguinte problema: os agentes habilitados para realizá-la são justamente aqueles que estão distanciados da realidade política e, a não ser que deixem de lado o tribunal pela tribuna e desvirtuem sua própria função burocrática, não irão desenvolver a sensibilidade para a resolução dos problemas morais ou de valores.

Para Dworkin, um Judiciário independente pode garantir condições racionais para que o indivíduo identifique suas ações políticas com as produções legislativas da comunidade política. Tal formulação procura resolver a lacuna que existe entre a produção legislativa com pretensão de universalização e a perspectiva subjetiva individual apostando nos direitos e no papel do Judiciário em resolver conflitos. A garantia do autogoverno para todos é assegurada pelo Judiciário. O controle de constitucionalidade surge, por isso, como o instrumento que, se bem conduzido, pode resolver o problema da dificuldade contramajoritária. ${ }^{16}$

A democracia continua a se atrelar a uma ideia normativa, a uma substância, por mais que seu conteúdo possa ser objeto de disputas. A democracia, em seu núcleo duro, demanda procedimentos para a tomada de decisões coletivas, para que os muitos possam decidir, ou seja, orientar as ações realizadas na esfera política. Uma decisão política não pode ser tratada como democrática se determinado conjunto de valores não é observado.

O constitucionalismo defende, diante desse cenário, que o governo seja submetido às razões expressas nas normas, estabelece valores a priori, os quais não são negociáveis e irão formar os princípios basilares do sistema normativo. Para Jürgen Habermas, tais elementos garantem a base do constitucionalismo, a cultura política compartilhada entre cidadãos que se reconhecem como membros da polis (HABERMAS, 1998). Trata-se dos compromissos, das promessas constitucionais que uma comunidade política realiza para si própria. Há uma evidente aposta, nessa esfera, na possibilidade da conquista da liberdade através das leis, a qual leva novamente ao paradoxo da democracia.

Para formar um Estado democrático de direito, ante a insuficiência democrática do puro Estado de direito, deve-se não apenas reconhecer a importância da tensão existente entre aspectos democráticos e constitucionalistas na organização da vida 
coletiva, mas, de igual maneira, assumir a importância dos paradoxos constitutivos de toda comunidade política. Com isso não se busca solapar o conjunto presente de organizações políticas, porém apontar indicativos das razões do paradoxo originário da política.

\section{Processos e substâncias}

Nessa seara, o conceito de democracia deliberativa foi revisitado, pois o desafio que ela procura enfrentar é o de reconciliar o direito e a política, de forma a produzir resultados legítimos derivados da participação dos membros da comunidade política, que apresentam suas diferentes razões para determinar a edificação de uma identidade constituinte (HABERMAS, 1996).

A partir disso, Jon Elster afirma que assembleias constituintes podem envolver a democracia deliberativa de duas formas: primeiro, por meio de delegados eleitos democraticamente que irão produzir a Constituição formal; mas também a democracia deliberativa pode ser apresentada como um objetivo a ser alcançado pelos constituintes, como foi o caso dos pais fundadores nos Estados Unidos (ELSTER, 1999, p. 97).

Em contextos de deliberação, ameaças baseadas na força são inadmissíveis, não pelo fato de que elas são baseadas no autointeresse, mas porque aquilo que deve prevalecer é a razão, são os argumentos racionais apresentados pelos participantes da coletividade. Assim, fornece-se o privilégio para aqueles que vencerem a deliberação e não a "queda de braço". Um dos principais argumentos de Elster é que a estrutura deliberativa pode contribuir para a definição dos resultados, independentemente dos motivos que levam os participantes até a arena deliberativa (ELSTER, 1999, p. 104).

Logo, as deliberações sobre a produção de Constituições demandam a formação de um espaço que garanta a própria deliberação. Esse procedimento deve ir além da pura agregação e registro de votos. Outra característica desse espaço deliberativo é que as assembleias constituintes tendem a negar a presença de autoridades superiores que venham a limitar, por meio de procedimentos ou conteúdos, as deliberações que serão realizadas (ELSTER, 1999, p. 106). Contudo, nem sempre é possível observar uma completa "liberdade inicial" para a produção da Constituição.

Trata-se da incorporação das razões comunicativas de Habermas, com sua pressuposição pragmática de que todas as interações humanas são mediadas pela linguagem, logo, elas possuem como finalidade a construção de uma compreensão compartilhada no contexto em que tais interações ocorrem (HABERMAS, 1994). A teoria do discurso apresenta os procedimentos e os pressupostos comunicativos da formação de opiniões e vontade em termos democráticos, como os pontos mais importantes para a racionalização discursiva das decisões de uma sociedade.

A ideia de uma comunidade política organizada pela democracia deliberativa possui como virtude, na perspectiva de seus defensores, a capacidade de conciliar a 
autodeterminação política e a vida em comunidade. Assim, a democracia deliberativa é uma forma de organizar a comunidade política que, ao demandar justificações aceitáveis pelas outras pessoas que compõem a comunidade, garante a autonomia política de cada um manifestar suas opiniões.

Ela não nega que a vida política conjunta possua aspectos coercitivos, porém demanda razões daqueles que são governados por decisões coletivas que divergem destas decisões. Eles precisam apresentar suas razões em termos de valores políticos que melhor se adequariam para organizar a esfera pública. Joshua Cohen explica que a democracia deliberativa permite a "adesão plena" à comunidade política, pois não se trata apenas da igualdade na comunidade no sentido da submissão ao poder, mas também no sentido da possibilidade do exercício do poder pelos cidadãos (COHEN, 1999, p. 222-223).

Observa-se, com isso, a importância que decisões coletivas legítimas passaram a ocupar no cenário contemporâneo na busca pela legitimação da ordem política. Trata-se da ação dos designers institucionais na construção dos fundamentos de um espaço público deliberativo, em que o processo de tomada de decisões pode ser aprimorado e, dentro dessa perspectiva, também a qualidade da democracia.

Uma maneira procedimentalista de se aproximar dessa questão ocorre através da redução da exposição dos agentes que tomam decisões a fatores que promovam distorções comunicacionais ou cognitivas. Isso é o que pode ser chamado de design negativo (ESLTER, 2013, p. 12), o qual pode ser observado na busca da retirada de obstáculos para a tomada de boas decisões políticas. O design negativo pode ser utilizado tanto em decisões das Cortes como em decisões políticas de assembleias.

De acordo com Roberto Gargarella, a construção conceitual dos pais fundadores que os levou a depositar suas esperanças no Judiciário residia justamente no caráter contramajoritário que os magistrados poderiam exercer (GARGARELLA, 1999, p. 269). Como os membros da Suprema Corte são eleitos de maneira indireta, membros dos setores minoritários (os proprietários) poderiam ocupar esse poder e defender suas perspectivas. Como presumiam que todos são motivados pelo autointeresse, logo, as minorias seriam protegidas, uma vez que os juízes buscariam proteger o seu próprio grupo.

É muito provável que, de fato, a motivação original dos pais fundadores fosse enredada por um interesse que é tratado contemporaneamente como egoísta, o qual levou à construção de mecanismos de governos que pudessem dar guarida aos interesses de poucos, como a propriedade privada. Contudo, a função contramajoritária das Cortes foi, com o tempo, deslocada da proteção dos poucos proprietários para minorias não representadas politicamente - o que não é, definitivamente, o caso dos poucos proprietários -, ou seja, atores políticos marginalizados da sociedade civil ou impedidos de ocupar espaços de poder substantivos na comunidade política, nas posições de déficit representativo da comunidade política. 
No que tange às assembleias constituintes, percebe-se uma especificidade por elas poderem decidir sobre o seu próprio procedimento para a tomada de decisões. Característica que tende a ser comum a todas as constituintes é a negação de autoridade a figuras exteriores - quem não pertence ao nós ou ao povo não tem garantia de vez e voz nas deliberações que determinam a produção constituinte. Exceções podem existir nos casos em que o povo precisa se reconstruir sob a intervenção de um Estado estrangeiro. No caso dos pais fundadores dos Estados Unidos, eles enfrentaram o problema de decidir como decidir. A questão se apresentou com celeuma pois os delegados reunidos tiveram de resolver se cada Estado teria um voto, cada delegado teria um voto ou cada Estado teria um voto proporcional à sua população. Aquilo que acabou por prevalecer foi que cada colônia ou província teria um voto (JENSEN, 1959, p. 59).

Enquanto no plano externo as constituintes tendem a restringir as influências de atores políticos internacionais no seu processo de autodeterminação, no plano interno as constituintes adotam postura distinta. Em muitos casos, as decisões procedimentais que restringem decisões substantivas de uma coletividade são determinadas por corpos externos, como no caso do controle de constitucionalidade. Como observa Elster, a decisão sobre como decidir e quem decide são próximas, porém, distintas (ELSTER, 2013, p. 24). Ambas podem levar a questionamentos infinitos, mas quem decide pode ser resolvido com a autofundação da assembleia (ELSTER, 1994, p. 28).

Ainda, o processo coletivo de tomada de decisão deve ser pensado como a interação horizontal entre diferente indivíduos; desse modo, ficam excluídas as formas de decisão impostas ou ditatoriais (ELSTER, 2013, p. 28). Porém, na prática, a distinção entre o processo de tomada de decisão de um coletivo e de um ditador pode galgar tons cinzentos - eis que um membro de uma coletividade pode dominar a entidade por anos e sempre vencer em todas as decisões, assim como um monarca pode ser apenas um adereço figurativo de determinada identidade nacional, sem qualquer poder de decisão efetivo, mas com o caráter simbólico de promover a reunificação da nação.

Mas como podem ser formulados bons processos de tomada de decisão coletiva? Aspectos diversos podem ser observados, como: decisões boas no processo de sua elaboração, ou seja, são garantidos procedimentos adequados para a decisão; decisões boas para aqueles que estão decidindo, em que o resultado dos processos decisórios agrada aos atores políticos que formularam a decisão; e decisões boas para seus destinatários, isto é, as pessoas que irão sofrer as consequências fáticas da alteração do mundo que a decisão irá promover.

Isso pode ser observado na decisão dos pais fundadores dos Estados Unidos na definição de quem teria direito ao voto. Eles realizaram, nos termos de Alexander Keyssar, uma importante façanha de reunião ideológica ao defender uma política não igualitária em termos igualitários. ${ }^{17}$ Portanto, aquilo que estava enredado no plano 
subjetivo dos pais fundadores eram seus interesses particulares, porém eles apelaram para os interesses dos destinatários de suas decisões - os futuros eleitores: brancos e proprietários - para decidir tal questão.

Sabe-se que a votação por maioria é um instrumento frágil para a determinação da vontade geral. De acordo com Elster, não se trata de uma questão de incoerência, uma vez que o método da maioria é coerente, mas de um problema de informação (ELSTER, 2013, p. 39). A votação por maioria é limitada pois o máximo de seu alcance é "um ou outros", pode-se votar em uma política pública ou em outra, em um candidato ou em outro. Uma forma de remediar o problema é o aprimoramento dos procedimentos decisórios.

\section{Constituindo a Constituição Pelo Judiciário:}

ENTRE RAZÕES E RESULTADOS

Em um sermão controverso, o bispo de Bangor, País de Gales, Benjamin Hoadly afirmou que: "whoever has an absolute Authority to interpret any written, or spoken Laws; it is $H e$, who is truly the Law-giver, to all Intents and Purposes; and not the Person who first wrote, or spoke them". ${ }^{18}$ A preocupação do bispo estava na ausência do Autor das escrituras e no fato de que os intérpretes poderiam se tornar soberanos. Hoadly era um advogado do direito dos revolucionários contra governos abusivos, além de que sua defesa, feita a pedido do rei George I, era a de que não existia uma justificação bíblica para qualquer governo da Igreja: esta estava identificada com o Reino dos Céus (Heaven), logo, não pertencia a este mundo, de modo que Cristo não havia delegado sua autoridade para nenhum representante terreno. Pode-se observar, novamente, o afastamento da teologia política, porém, agora, com origem em instituições religiosas e com finalidades diversas.

Na sequência dessa tradição, John Chipman Gray (1909, p. 120) e o Justice Oliver Wendell Holmes argumentavam que os juízes, e não os legisladores, eram os verdadeiros criadores de leis, adotando vetor no sentido inverso daquele sugerido por Rousseau, que atribuía ao legislador o papel de produtor de futuros cidadãos. Entendia-se que os juízes "davam vida" para a letra morta das leis, pois as leis precisavam de um intérprete e seu sentido era declarado pelas Cortes. Além disso, no possível embate entre o juiz e o legislador, o magistrado possuiria a "última palavra". Pois, a Suprema Corte dos Estados Unidos, em um conjunto de casos, afirmou ser a última intérprete da Constituição. ${ }^{19}$

Keith Whittington lembra que o poder de controle de constitucionalidade não é uma criação que pode ser derivada dos "Pais Fundadores" - eles, assim como o bispo Hoadly, não imaginavam que o Judiciário viesse a possuir uma "autoridade Absoluta" para realizar interpretações e, mesmo em Marbury v. Madison (1803), o dever de o Judiciário dizer aquilo que a lei é, e o seu respectivo poder para interpretar a Constituição, 
eram modestos (WHITTINGTON, 2005, p. 118). A preocupação acerca da possibilidade de as Cortes se tornarem soberanas quando vinculadas à tarefa de interpretação da Constituição e de realização do controle de constitucionalidade auxilia não apenas no entendimento da relação entre constitucionalismo e democracia, mas também na análise da prática efetiva das decisões e de suas argumentações.

Enquanto os federalistas observavam uma separação clara entre o Legislativo e o povo (HAMILTON; MADISON; JAY, 2003), nas gerações subsequentes se passou a compreender que o Legislativo era uma extensão do povo, enquanto a prática do Judiciário de declarar leis inconstitucionais se tornou antagônica com a "manifestação da vontade" popular. Diante da desconexão entre constitucionalismo e soberania popular, defluíram dificuldades na justificação da interpretação da lei por uma autoridade judicial forte, a qual se distanciou do povo.

A prática do controle de constitucionalidade e sua tensão com a democracia produz, ao menos, dois tipos de questionamentos. O primeiro, identificado por Alexander Bickel, é a dificuldade contramajoritária, ${ }^{20}$ perspectiva na qual a declaração de inconstitucionalidade de leis, as quais possuem como pressuposto a legitimação democrática, torna-se a obstrução da manifestação da vontade pelo povo.

O segundo problema é o do "governo pelo Judiciário". A preocupação está na possibilidade de os juízes legislarem ao tomar decisões discricionárias sobre questões políticas. Logo, ao interpretar a Constituição, os juízes podem ser vistos como exercendo uma prática antidemocrática não apenas por obstruir a vontade do povo, mas por atuar no lugar dos legisladores, ao tratar de assuntos que não estão explicitados no texto constitucional ou estabelecer dispositivos normativos não previstos pela Constituição (WHITTINGTON, 2005, p. 121).

Desse modo, a produção constituinte pode ser vista como um momento estendido de acordos incompletamente teorizados em larga escala (SUNSTEIN, 1995). Chega-se a consensos sobre a positivação de valores, de instituições burocráticas que irão definir o design da máquina estatal, mas a palavra final sobre a teoria que preenche os institutos é deixada em suspenso, na maioria dos casos, não pode ser alcançada.

Outra questão que precisa ser enfrentada na formulação de decisões coletivas é a capacidade de os atores políticos manipularem, de maneira estratégica, os próprios procedimentos para alcançar os resultados que eles desejam. São métodos indiretos em que, apesar de as regras do jogo não permitirem alcançar determinado resultado, se procura mudar o próprio jogo ou apelar a uma instância externa.

Mudanças casuísticas nas leis eleitorais podem ser observadas na França, mas também na política brasileira; por isso, o princípio da anualidade guarda sua importância instrumental negativa de atrasar ataques legislativos "eleitoreiros". A redistribuição estratégica de distritos para favorecer certo partido ou grupo político é prática observada nos Estados Unidos, conhecida como gerrymandering, e procura antecipar vantagens políticas ao manipular as fronteiras eleitorais (TUSHNET, 2009, p. 64). 
Porém, o próprio Judiciário pode ser alvo das manipulações oportunistas. O presidente francês Valéry Giscard d'Estaing facilitou o acesso a recursos para o Conselho Constitucional em 1974, tendo em vista que, se a direita se tornasse minoritária, ela teria no Conselho uma via de escape contra um potencial domínio futuro da esquerda no país. Tal manobra não é exclusiva da direita francesa, os comunistas na Hungria decidiram que, com o fim do comunismo, seria criada uma Corte Constitucional forte, a qual serviria como meio de proteção de represálias ante a perda de seus poderes. ${ }^{21}$

Percebe-se, com isso, que as instituições possuem a faculdade de determinar preferências em termos normativos. Logo, os processos de tomada de decisões coletivas precisam, na medida do possível, ser blindados contra os interesses pessoais daqueles que tomam as decisões. Contudo, a tentativa de blindagem contra os interesses pessoais nem sempre consegue se realizar de maneira adequada.

Por isso, busca-se implementar mecanismos institucionais que inibam a produção legislativa que tenha como finalidade enriquecer os próprios parlamentares ou mecanismos que evitem que parlamentares recebam propina para votar. Assim, procurase afastar as decisões de interesses particulares, de modo que o design institucional possa favorecer instrumentos negativos por meio da publicização dos processos.

Dessa maneira, o próprio uso de argumentos que se destinam ao interesse público, em vez de ser autointeressado, precisa enfrentar barreiras nos modos de ação política, por meio dos limites da imperfeição e da consistência (ELSTER, 2013, p. 92). Quando um agente político se utiliza de um determinado argumento voltado para o interesse público, torna-se difícil para ele abandonar o mesmo argumento no futuro, ainda que os políticos não precisem guardar coerência profunda em suas argumentações.

Logo, não apenas a Constituição importa, ${ }^{22}$ mas também o processo que definiu a sua adoção. Mesmo que os processos que a comunidade política tenha decidido para definir sua organização não necessariamente sejam derivados do texto constitucional, as Constituições são necessárias para prevenir aqueles que estão no poder de usar seus poderes para manter suas posições políticas permanentemente.

Deve-se observar que, em termos contemporâneos, é muito improvável aceitar a produção de uma Constituição (ou de uma Constituinte parcial) que não envolva discussões públicas, inclusive para trazer à tona posições políticas sub-representadas (ARATO, 2000, p. 250). Porém, os próprios parlamentares precisam ter a garantia da sua liberdade para deliberar; por isso, procedimentos que habilitem, ao mesmo tempo, os parlamentares e o povo na constituição da Constituição precisam ser articulados.

Deve-se lembrar que várias instituições constituem corpos que continuam a tomar decisões. Elas não são formadas para tomar apenas uma decisão e se dispersar. As Cortes Constitucionais servem de exemplo nesse sentido, eis que suas decisões têm o potencial de formar precedentes com o poder de vincular decisões futuras, e, em menor escala, remodelar diretamente aspectos determinantes da comunidade política. 
Uma das variáveis no aperfeiçoamento dos procedimentos é se as decisões são tomadas de acordo com os resultados que elas irão produzir ou de acordo com princípios que orientam a instituição. O primeiro é tratado como um procedimento fundado na conclusão, enquanto o segundo é tratado como um procedimento fundado nas premissas. A partir dessa distinção, Elster sugere o resgate do "paradoxo de Poisson" (ELSTER, 2013, p. 63).

Se os juízes seguirem os processos de tomada de decisão baseados na conclusão, o acusado será inocentado; porém, se eles decidirem de acordo com o voto da maioria, o acusado será condenado. O paradoxo pode ser apresentado por meio de três perguntas: i) X traiu Y?; ii) trair alguém significa violar um direito?; iii) X é culpado? O juiz 1 responde "sim" para as três questões. O juiz 2 responde "sim" para a primeira e "não" para as outras duas. O juiz 3 responde "sim" apenas para a segunda. Observam-se, com esse resultado, duas respostas positivas para a primeira questão e duas negativas para a terceira.

A diferença entre os votos é a seguinte: o primeiro juiz possui uma perspectiva linear, o fato foi consumado, a lei deve ser aplicada, logo, o acusado é culpado. O segundo juiz acredita que $X$ traiu seu cônjuge, porém não vê na traição uma ofensa ao direito e disso não pode derivar a culpa de X. O terceiro juiz, contudo, não altera o status jurídico, a lei é mantida, mas o acusado foi considerado faticamente inocente por ele. O paradoxo, derivado da agregação, não engendra meras possibilidades abstratas, eis que pode ocorrer facilmente e, em geral, não existe qualquer razão para preferir os procedimentos baseados na agregação ou nas premissas (ELSTER, 2013, p. 64).

Assim, a ideia de que a legitimação das Cortes está baseada nas razões que elas apresentam para suas decisões pode ser contestada. Uma vez que as razões (premissas) não vinculam necessariamente a um resultado final. Podem existir interpretações distintas tanto sobre a questão fática quanto sobre a legalidade da norma pertencente ao ordenamento jurídico, ou seja, os juízes podem divergir tanto sobre o acontecimento da traição no mundo real como sobre a constitucionalidade da norma que pune a pessoa que traiu a outra.

Os processos coletivos de tomada de decisão, ao adotarem uma perspectiva deliberativa, tendem a ser céticos a respeito de procedimentos que se limitam a agregar as preferências ou interesses dos participantes. Segundo James Johnson, essa forma não preencheria as demandas morais necessárias para a legitimação dos resultados das decisões coletivas, por isso, preferem acordos pautados nas razões em vez da simples agregação dos votos (JOHNSON, 1999, p. 162-163). Mesmo porque os resultados da simples agregação são ambíguos, pois diferentes métodos de contagem dos votos podem produzir resultados drasticamente distintos das preferências iniciais dos atores políticos envolvidos (JOHNSON, 1999, p. 176).

De acordo com Elster, é frágil pressupor que as razões sempre irão justificar as decisões para a implementação de políticas, de modo que o paradoxo de Poisson não 
pudesse emergir, enquanto no campo jurídico não existem justificações para que a "mesma" corte seja a responsável pela apreciação dos argumentos fáticos e pela decisão final. ${ }^{23}$

\section{A Transcendência dos MOtivos Determinantes}

O problema atinente ao "vazio de poder" perpassou diferentes momentos da modernidade, e aquilo que pode ser observado nos últimos anos no Brasil foi uma progressiva ascendência do Judiciário como ocupante de parcela importante de espaços de poder não preenchidos pelos outros Poderes. Para além do registro temporal que pode ser identificado nas mudanças legislativas que aperfeiçoaram a jurisdição constitucional $^{24}$ e com o advento da reforma do Judiciário, ${ }^{25}$ o próprio STF se projetou como instância para a resolução de conflitos que até então não tivera oportunidade de ocupar adequadamente no país.

Em face de fenômenos como a judicialização da política - a qual posiciona o Judiciário como um Poder central para a solução de questões de alta densidade política -, novos questionamentos surgiram (FEREJOHN, 2002). No mesmo sentido, o reconhecimento da dificuldade contramajoritária passou a demandar algum grau de democracia na elaboração da jurisdição constitucional, pensada até então como uma ferramenta distanciada e oposta a levantes populares. ${ }^{26}$

Formou-se, por isso, um movimento de afirmação do papel do Judiciário em sua capacidade de decidir acerca de valores substantivos constitutivos da organização da comunidade política. Esse movimento foi interpelado por demandas no sentido da abertura do Judiciário tanto para discursos externos, uma vez que os fóruns deliberativos tradicionais poderiam estar obstruídos, como para conferir espaço a grupos minoritários, pois a jurisdição constitucional poderia cumprir, em certos casos, a função de correção de eventuais abusos perpetrados pela maioria (ELY, 2010).

A questão que pode ser derivada dessas transformações não se volta para a reestabilização de um lugar idealizado do Judiciário em sua relação com os outros Poderes ou com o povo, ao contrário, o diagnóstico se dirige para a presente inadequação que ocorre entre um conjunto de instrumentais que o Judiciário passou a fabricar para auxiliá-lo na realização das atividades jurisdicionais, sem que isso tenha sido acompanhado de uma redefinição da forma de compreender o próprio fenômeno jurídico.

Em termos metafóricos é possível dizer que, apesar de terem sido realizadas modificações na "casa de máquinas" institucional, os maquinistas continuam a pensar da mesma maneira que antes (TROPER, 1999). A implementação de novos dispositivos ou "tecnologias" precisa ser sintonizada com um renovado modus operandi por parte do Judiciário, sob pena de reproduzir o discurso de preenchimento do espaço vazio de poder. 
A oposição ao uso da doutrina da transcendência dos motivos determinantes indica como não basta mudar apenas os instrumentais e as tecnologias. Conforme previamente exposto, a doutrina da transcendência dos motivos determinantes das decisões tem como finalidade a transcendência da eficácia dos julgados de casos singulares. Isso possibilita que a fundamentação decisória seja adotada em outros casos, ao ser reconhecida força vinculante para além da parte dispositiva da decisão, englobando também a ratio decidendi, que passaria a vincular o Judiciário e a Administração Pública. Qual argumento justifica a recusa de parcela do STF no que tange à transcendência?

O leading case em que a matéria foi discutida no STF foi a Reclamação 1.987/DF, 27 a qual foi conhecida e julgada procedente por maioria dos votos (Maurício Corrêa, Gilmar Mendes, Celso de Mello, Cezar Peluso e Nelson Jobim), aceitando-se, portanto, a possibilidade da transcendência dos motivos determinantes sobre a parte dispositiva. O Ministro Carlos Velloso foi favorável à procedência da Reclamação, mas não à transcendência dos motivos determinantes, no que foi seguido pela minoria (Sepúlveda Pertence, Marco Aurélio e Carlos Britto).

Em outro caso, na Reclamação $2.475 / \mathrm{MG},{ }^{28}$ foi reafirmada a tese de que a transcendência alcança apenas a parte dispositiva da decisão, não abrangendo a fundamentação. Com a diferença de que o Ministro Gilmar Mendes afirmou, em voto vista, diante do Agravo Regimental interposto perante a Reclamação, sua interpretação de que os efeitos vinculantes alcançariam os fundamentos determinantes da decisão. Sua tese foi seguida pela minoria (Cármen Lúcia, Joaquim Barbosa e Celso de Mello); por isso, foi negado provimento ao agravo regimental.

Na decisão do Agravo Regimental na Reclamação 2.990/RN, ${ }^{29}$ seu relator, Ministro Sepúlveda Pertence, fez remissão à decisão da Reclamação 2.475 para afirmar que o STF havia rejeitado a tese da eficácia vinculante dos motivos determinantes nos casos de controle abstrato de constitucionalidade. Com a Reclamação 3.014/SP, 30 o STF sedimentou sua posição no sentido de negar a transcendência dos motivos determinantes, bem como a possibilidade da Reclamação ${ }^{31}$ configurar via ajustada para realizar fiscalização de constitucionalidade normativa. ${ }^{32}$

Um dos principais receios atrelados ao uso da doutrina da transcendência dos motivos determinantes estaria na possibilidade de o STF passar a ter o poder de transformar em súmula vinculante qualquer premissa de uma decisão. O problema, porém, se coloca em sentido inverso, pois, com a negação da transcendência, confere-se a permissão para que as decisões proferidas pelo STF tenham caráter de meros argumentos desvinculados do resultado final e também sem força vinculante para a formação dos precedentes.

O paradoxo de Poisson pode ser observado em situações desse tipo. Quando o Tribunal trata suas fundamentações como obiter dicta e não razões de decidir, o paradoxo da agregação pode ocorrer com grande facilidade. Os fundamentos utilizados por cada um dos onze ministros do STF podem, em um cenário trágico, estar completamente 
desconectados de suas votações finais. A ratio decidendi é a parte da decisão de um Tribunal que juízes decidindo casos posteriores precisam necessariamente observar. Por outro lado, as obiter dicta são partes da decisão que não possuem qualquer força vinculatória para as decisões subsequentes. No que tange ao nível de vinculação dos precedentes, as obiter dicta podem ser ignoradas sem quaisquer consequências.

A preocupação em ressaltar e trazer a responsabilidade dos juízes pela integralidade de seus argumentos está fundada na possível ocorrência desse paradoxo. Um dos problemas do uso dos precedentes no Civil Law está na própria negação da doutrina da transcendência dos motivos determinantes. Nesse caso, verifica-se que foi formado um precedente a respeito da matéria, que se encontra em vigor na Corte, que não guarda clareza em seus argumentos originários e que tem por base votações pouco consensuais sobre o assunto. Em cenários nos quais as razões de decidir tivessem maior peso, mesmo as razões para afastar uso da doutrina da transcendência dos motivos determinantes teria maior cuidado na exposição dos argumentos justificatórios relevantes e dos argumentos complementares.

Ademais, o respeito aos precedentes trata da obrigação do juiz em seguir as decisões que foram tomadas anteriormente sobre os mesmos assuntos. Os precedentes podem ser observados desde uma perspectiva vertical, em que os tribunais inferiores são compelidos por Cortes em hierarquias superiores sobre a matéria decidida. Porém, também é relevante a construção de precedentes em sentido horizontal, com o stare decisis, de modo que a obrigação da Corte não é a de se submeter a uma instância hierárquica, mas a de seguir o conjunto decisório estabelecido pelo próprio tribunal em ocasiões anteriores. Tanto em seu sentido vertical como no horizontal, os precedentes precisam ter seu caráter vinculativo observado - trata-se da autoridade conferida às decisões formuladas anteriormente. ${ }^{33}$

A lógica que subjaz o não uso da doutrina é próxima daquela que se afirma como ocupante do espaço de poder vazio, ou da detentora da continuidade do poder constituinte. Aqui, observa-se o uso inadequado dos precedentes no Brasil ou de seu papel como textos retóricos esvaziados de força normativa.

Uma explicação possível para tal prática está na tradição jurídica nacional. Não apenas em questões atinentes à formação dos juristas, que são levados a uma idolatria dos textos e a uma crença cega na busca de respostas no questionável projeto do "Código" e da codificação, mas também pela forma ainda pouco refinada e prática que se trabalha com os precedentes. Se não temos uma tradição de construir decisões a partir de precedentes, isso não quer dizer que não dispomos de decisões anteriores que não apenas podem, mas devem ser utilizadas para guiar a formulação de decisões posteriores.

Imagine-se o juiz que acredita que todos os casos que lhe são apresentados são difíceis e que todas as decisões que ele precisa tomar iniciam do "zero" a construção da narrativa jurídica sobre o assunto apresentado para seu julgamento. Isso repercutiria 
em uma atividade jurídica impossível, que se colocaria perpetuamente diante de um ponto inicial e que se habilitaria a retóricas autolegitimantes para tomar decisões. $\mathrm{O}$ juiz passaria a cumprir a função de criador, de fundador (nomothete), ao se projetar como aquele que deve ocupar o espaço vazio de poder.

\section{CONSIDERAÇÕES FINAIS}

O artigo procurou analisar a passagem que ocorre na tradição do Civil Law no sentido da utilização de instrumentais que são próprios do Common Law. ${ }^{34}$ No caso brasileiro, tal passagem parece ser mediada - paradoxalmente - por uma nova codificação (Código de Processo Civil, Lei n. 13.105/2015). Trata-se de um paradoxo pois aposta na codificação como maneira de determinar como deve ser a produção jurisdicional. ${ }^{35}$ A obrigação da justificação das decisões, de serem apresentadas as razões, os fundamentos da decisão e não apenas seus resultados, pode ser verificada no cuidado institucional que qualquer Tribunal que se preocupe com os precedentes deve possuir para não gerar paradoxos como o paradoxo de Poisson. Ainda que tais mudanças sejam advindas de uma determinação legislativa, o ideal seria uma transformação da compreensão do papel dos magistrados e sua responsabilidade em apresentar argumentos que justifiquem suas decisões.

Por fim, uma vez que o Brasil passou a incorporar em seu ordenamento jurídico um conjunto de mecanismos para a resolução de conflitos provenientes do Common Law, não seria demasiado pleitear uma alteração do papel dos precedentes e das razões fundamentais da decisão. Isso pode ser feito, mesmo que sob a égide de uma nova codificação. A interpretação do juiz, todos sabem, precisa ser justificada e deve ser fundamentada em outras fontes que não apenas as vontades pessoais do magistrado. Embora seja inafastável a condição em que o magistrado possui à sua disposição uma grande quantidade de razões e fatos para sustentar diversas interpretações, as narrativas jurídicas que se encontram sob sua responsabilidade demandam justificações que serão interpretadas por leitores com diferentes valores.

Uma sugestão final, que pode auxiliar nas alterações que devem ser realizadas na maneira de operacionalização do Judiciário, seria a percepção da atividade jurisdicional como um diálogo jurídico continuado (ESKRIDGE, 1987, p. 1537), e não um monólogo. ${ }^{36}$ No caso do diálogo, o intérprete está, ao mesmo tempo, vinculado a explicar e justificar suas decisões, diante da comunidade interpretativa composta por outros juristas. Logo, não basta a atenção para as razões, a justificação dos motivos da decisão é o fator que confere legitimidade para as decisões. Se isso não resolve o problema da agregação nem o problema do déficit democrático das decisões, é, ao menos, um bom começo para revisar uma tradição acostumada com pessoas falando sozinhas e descompromissadas com os resultados de seus dictum. 


\section{NOTAS}

1 "The issue, briefly described, is one of 'constitutional bootstrapping', the process by which a constituent assembly severs its ties with the authorities that have called it into being and arrogates some or all of their powers to itself.” (ELSTER, 1994, p. 57).

2 Para Aristóteles, a cidade-estado precisa de um legislador, qualquer tipo de comunidade apenas terá ordem se tiver alguma autoridade que produza normas, as quais serão definidas por uma "constituição". Porém, deve-se buscar a explicação que levou a cidade-estado a ter uma "constituição". A primeira pessoa que cria a cidade-estado é o promotor de grandes benefícios, o legislador (nomothete) é comparado com Sólon ou Licurgo, fundadores da “constituição" (ARISTOTLE, 1932, p. 165). O legislador é comparado com o artesão, o criador (demiourgos), um tecelão ou o construtor de navios, aqueles que moldam seus materiais em uma obra acabada (ARISTOTLE, 1932, p. 199).

3 A referência que é feita no início sobre os paradoxos na relação entre constitucionalismo e democracia também é comumente referida como uma "tensão" entre ambos. Ao longo do texto são apresentadas outras formas de paradoxos.

4 “5. Efeito vinculante das decisões proferidas em ação direta de inconstitucionalidade. 6. Eficácia que transcende o caso singular. 7. Alcance do efeito vinculante que não se limita à parte dispositiva da decisão. 8 . Aplicação das razões determinantes da decisão proferida na ADI 1662.” (Rcl 2.363/PA, Rel. Min. Gilmar Mendes, j. 23.10.2003, DJ 01.04.2005).

5 Sobre a dinâmica entre conflito e estabilização ver Kozicki (2000).

6 Lefort assinala que o fenômeno religioso continua a existir por meio de novas crenças e novas representações. Essas crenças podem, a qualquer momento, reemergir em formas tradicionais ou renovadas. A noção moderna de política se apresentou como uma espécie de desconhecimento de uma parte do social, dos processos que fazem com que as pessoas consintam ante determinado regime (LEFORT, 1988).

7 Sobre a centralidade do poder constituinte para o constitucionalismo, ver Loughlin (2014).

8 "At once, in place of the individual personality of each contracting party, this act of association creates a moral and collective body, composed of as many members as the assembly contains votes, and receiving from this act its unity, its common identity, its life and its will. This public person, so formed by the union of all other persons, formerly took the name of city, and now takes that of Republic or body politic; it is called by its members State when passive, Sovereign when active, and Power when compared with others like itself." (ROUSSEAU, 1923, p. 15-16).

9 "The legislator is the engineer who invents the machine, the prince merely the mechanic who sets it up and makes it go. [...] He who dares to undertake the making of a people's institutions ought to feel himself capable, so to speak, of changing the human nature, of transforming each individual, who is by himself a complete and solitary whole, into part of a greater whole from which he in a manner receives his life and being;" (ROUSSEAU, 1923, p. 35). Como observa Frederick Neuhouser: "[...] Rousseau's view will be that membership in the state embodies 'moral freedom', which is defined as a species of autonomy, or as 'obedience to the law one has prescribed for oneself'. At the same time, political membership is a precondition of 'civil freedom', which Rousseau takes to be the ability of individuals to act unconstrained by the particular wills of others within a sphere of activity deemed by society to be external to the vital interests of the community as a whole." (NEUHOUSER, 1993, p. 366).

10 O paradoxo da política, desde uma perspectiva democrática, demanda a compreensão inicial de que o Povo, os atores e sujeitos políticos por excelência, se apresenta como uma massa amorfa de pessoas reunidas, uma multidão. De acordo com Honig, o paradoxo da política postula que a democracia está sempre vinculada ao problema de como diariamente (re)configurar uma multidão em um povo (HONIG, 2009).

11 Nesse sentido ver a crítica formulada em Kozicki (2000).

12 Uma das melhores sínteses do debate entre constitucionalismo e democracia foi apresentada por Frank Michelman (1999). 


\author{
13 Ver: Dworkin (1996); Post (1995); Ely (2010).
}

14 Segundo Michelman: 'Daunting though it may be, the answer seems to be 'yes,' in view of the moral and material importance that people quite reasonably attach to the contents of many of these basic laws, these laws of lawmaking. And yet I suspect we will always feel [...] an impulse to exclude the laws of lawmaking from democracy's procedural purview - to restrict the domain of procedurally democratic decision to whatever further political choices the laws of lawmaking leave open, while leaving those laws to be decided by right and true reasoning about what it means for a lawmaking system to be democratic" (MICHELMAN, 1999, p. 24).

15 Ver a análise do caso Riggs v. Palmer realizada por Dworkin (1978).

16 A posição de Michelman é a de que: “On the face of it, Dworkin's message is a happy one. It offers resolution of an apparent contradiction between two of our deepest (professed) political desires - for a government of laws, for self-government. His arguments seems meant to reassure and persuade us that we really can reconcile a democratic aspiration to political self-government by everyone with the practice of letting a few judges decide the applied contents of the country's basic laws. But I think the real, darker-hued, message is that there is no such reconciliation to be had. And this bring us back at last to the crushing logical objection I mentioned before, against the very idea that the contents of the laws of lawmaking could themselves be within the keeping of a democratic procedure to decide." (MICHELMAN, 1999, p. 32). Cf. Bickel (1986).

17 Pautados em William Blackstone, os pais fundadores afirmavam que aqueles que não possuíam meios para se sustentar não tinham como desenvolver sua própria vontade; logo, o direito ao voto demandaria certos prérequisitos, no caso, a propriedade. Contudo, esse argumento coexistia com outro, que o contradizia, de que os pobres poderiam representar uma ameaça aos proprietários de terra; logo, eles teriam muitas vontades que poderiam ameaçar os proprietários. O caso da Rebelião de Shays em Massachusetts servia como exemplo de que homens em situações econômicas adversas poderiam se reunir em torno de seus interesses (KEYSSAR, 2000, p. 10-11).

18 "quem possui uma Autoridade absoluta para interpretar quaisquer Leis escritas ou faladas, é o verdadeiro Legislador, para todas as Intenções e Propósitos; e não a Pessoa que primeiro as escreveu ou falou.” (HOADLY, 1717 , p. 12, tradução nossa).

19 Baker v. Carr (1962); United States v. Nixon (1974); Miller v. Johnson (1995). Nesse sentido ver as considerações de Herbert Hart: "A última forma, mas extremamente interessante, de cepticismo sobre as regras não repousa nem no caráter aberto das regras nem no caráter intuitivo de muitas decisões, mas no facto de a decisão de um tribunal ter uma posição única como algo dotado de autoridade e, no caso dos supremos tribunais, de definitividade. [...] Um supremo tribunal tem a última palavra a dizer sobre o que é o direito e, quando a tenha dito, a afirmação de que o tribunal estava 'errado' não tem consequências dentro do sistema: não são por isso alterados os direitos ou deveres de ninguém.” (HART, 2007, p. 154-155).

20 "The root difficulty is that judicial review is a counter-majoritarian force in our system. There are various ways of sliding over this ineluctable reality. Marshall did so when he spoke of enforcing, in behalf of 'the people', the limits that they have ordained for the institutions of a limited government. And it has been done ever since in much the same fashion by all too many commentators. Marshall himself followed Hamilton, who in the 78th Federalist denied that judicial review implied a superiority of the judicial over the legislative power-denied, in other words, that judicial review constituted control by an unrepresentative minority of an elected majority. 'It only supposes', Hamilton went on, 'that the power of the people is superior to both; and that where the will of the legislature, declared in its statutes, stands in opposition to that of the people, declared in the Constitution, the judges ought to be governed by the latter rather than the former'. But the word 'people' so used is an abstraction. Not necessarily a meaningless or a pernicious one by any means; always charged with emotion, but nonrepresentational-an abstraction obscuring the reality that when the Supreme Court declares unconstitutional." (BICKEL, 1986, p. 16).

21 "In the Constitution of the Fifth French Republic, the intended function of the Constitutional Council was to protect the executive against the legislature. Only four individuals - the President of the Republic, the Prime Minister, and the Presidents of the two legislative chambers - could bring a bill in before the Council for judicial review before its promulgation. Moreover, although the 1789 Declaration of Rights was cited in the Preamble to the 1958 Constitution, it had no valeur constitutionnelle. In practice, this arrangement left few opportunities to initiate 
judicial review. In 1971, however, the Council carried out what may be seen as a judicial coup d'état, by unilaterally incorporating the 1789 Declaration and other texts into its jurisprudence. Three years later, President Giscard d'Estaing expanded the scope of judicial review even more, by promoting an amendment of the constitution that allowed any group of sixty deputies or senators to bring in a bill before the Council.” (ELSTER, 2013, p. 81).

22 De acordo com Tushnet: “The Constitution matters because it provides a structure for our politics. It's politics, not 'the Constitution', that is the ultimate - and sometimes approximate - source for whatever protection we have for our fundamental rights. [...] The real question, then, is not why the Constitution matters, but how it matters. The Constitution matters because politics matters. The Constitution affects politics in many ways, most of those indirect, but we shouldn't overestimate how much it matters." (TUSHNET, 2010, p. 1-17).

23 Sobre a forma como os consensos são produzidos, o paradoxo da agregação de conclusões pode ser apresentado por meio de um exemplo histórico. De acordo com Elster, a Assembleia Constituinte francesa de 1789 enfrentava a discussão sobre a adoção do sistema unicameral ou bicameral. A Assembleia estava dividida em três grupos: a) reacionários, b) moderados e c) radicais. Os dois últimos queriam estabilizar o regime, enquanto os reacionários queriam desestabilizar o novo regime - estas eram as preferências iniciais de cada grupo. Reacionários e moderados compartilhavam a compreensão de que o bicameralismo seria estabilizador, enquanto os radicais acreditavam que este seria desestabilizador. Os radicais votaram pelo unicameralismo, os moderados pelo bicameralismo e os radicais pelo unicameralismo. O resultado final, pautado na agregação das conclusões, produziu o paradoxo, pois conseguiu agradar reacionários e radicais, os quais tinham premissas e intenções diversas sobre o novo regime. O paradoxo evidencia, portanto, que a agregação de premissas pode ser manipulada e não necessariamente manifesta de maneira adequada os interesses dos atores políticos envolvidos, se observada a divergência entre premissas e resultados (ELSTER, 2013, p. 64).

24 Com a Lei n. 9.868/99 (ADI e ADC) e a Lei n. 9.882/99 (ADPF).

25 Emenda Constitucional n. 45/2004.

26 "A constitutional court with judicial review illustrates a countermajoritarian structure providing diffuse protection. The court's power to reverse majority decisions infringing constitutional rights, for example, is a potent means of protecting a wide range of minority interests." (ALBERTS; WARSHAW; WEINGAST, 2012, p. 72).

27 “A decisão do Tribunal, em substância, teve sua autoridade desrespeitada de forma a legitimar o uso do instituto da reclamação. Hipótese a justificar a transcendência sobre a parte dispositiva dos motivos que embasaram a decisão e dos princípios por ela consagrados, uma vez que os fundamentos resultantes da interpretação da Constituição devem ser observados por todos os tribunais e autoridades, contexto que contribui para a preservação e desenvolvimento da ordem constitucional.” (Rcl 1.987/DF, Rel. Min. Maurício Corrêa, j. 01.10.2003, DJ 21.05.2004).

28 Rcl 2.475/MG, Rel. Min. Carlos Velloso, j. 19.11.2003, DJ 26.11.2003.

29 Ag Reg na Rcl 2.990/RN, Rel. Min. Sepúlveda Pertence, j. 16.08.2007, DJe 14.09.2007.

30 Rcl 3.014/SP, Rel. Min. Ayres Britto, j. 10.03.2010, DJe 21.05.2010.

31 Os argumentos utilizados para refutar a Reclamação 3.014/SP foram os seguintes: i) o endosso de tal tese implicaria suprimir instâncias; ii) aumentar-se-ia em demasia o número das Reclamações no STF; iii) extensão do rol de legitimados para propor ações diretas de inconstitucionalidade sem previsão normativa.

32 A tese da transcendência dos motivos determinantes continua a ser negada pelo STF: Ag Reg na Rcl 4454/RS, Rel. Min. Roberto Barroso, j. 03.03.2015, DJe 17.03.2015; Ag Reg na Rcl 16944/BA, Rel. Min. Rosa Weber, j. 24.02.2015, DJe 11.03.2015; MS 28064 AgR-ED/DF, Rel. Min. Cármen Lúcia, 06.11.2014, DJe 01.12.2014; Ag Reg na Rcl 11484/CE, Rel. Min. Ricardo Lewandowski, j. 05.08.2014, DJe 15.08.2014.

33 A demanda por observar os precedentes é uma forma de argumento e também uma forma de justificação (SCHAUER, 1987). 
34 Adotar instrumentais do Common Law via codificação é um paradoxo, uma vez que se está realizando uma aposta em uma tradição diferente, que enfatiza a importância dos precedentes. No Brasil, em vez da mudança da tradição da relação dos juízes com os precedentes, buscou-se estabelecer, via codificação, que os precedentes passarão a ser importantes.

35 Note-se que o paradoxo de Poisson pode ser observado tanto em tradições do Civil Law como do Common Law, de modo que é indiferente a codificação ou o precedente. O problema de fundamentação pode ocorrer em ambas as tradições.

36 Aquilo que se busca afirmar é algo mais singelo do que a ampla corrente identificada pela proposta dos “diálogos institucionais" está a sugerir, que é a interação dialógica entre o Judiciário e os demais poderes, como mecanismo de aperfeiçoamento democrático dos processos de tomada de decisão. O diálogo jurídico continuado trata da necessária lembrança de que os agentes públicos que tomam decisões - com foco especial no Judiciário precisam ter ciência de que sua decisão faz parte de um diálogo já iniciado por outros e do qual seu argumento (sua decisão) será mais um elemento importante na continuidade da "discussão" a respeito de certo tema polêmico levado para a apreciação jurisdicional. Sobre o interessante tema dos diálogos institucionais ver: Hogg e Bushell (1997); Bateup (2006); Silva (2009); Brandão (2012).

\section{REFERÊNCIAS BIBLIOGRÁFICAS}

ALBERTS, Susan; WARSHAW, Chris; WEINGAST, Barry R. Democratization and Countermajoritarian Institutions: the role of power and constitutional design in self-enforcing democracy. In: GINSBURG, Tom. Comparative Constitutional Design. Cambridge: Cambridge University Press, 2012.

ARATO, Andrew. Civil Society, Constitution, and Legitimacy. Lanham: Rowman \& Littlefield, 2000.

ARISTOTLE. Politics. London: William Heinemann, 1932.

BATEUP, Christine. The Dialogic Promise: assessing the normative potential of theories of constitutional dialogue. Brooklyn Law Review, v. 71, 2006.

BICKEL, Alexander. The Least Dangerous Branch: The Supreme Court at the Bar of Politics. New Haven: Yale University Press, 1986.

BRANDÃO, Rodrigo. Supremacia judicial versus diálogos constitucionais: a quem cabe a última palavra sobre o sentido da Constituição? Rio de Janeiro: Lumen Juris, 2012.

CHRISTENSEN, Ralph. Introdução. In: MÜLLER, Friedrich. Quem é o povo? São Paulo: Max Limonad, 1998. COHEN, Joshua. Democracy and Liberty. In: ELSTER, Jon. Deliberative Democracy. Cambridge: Cambridge University Press, 1999.

DWORKIN, Ronald. A Matter of Principle. Cambridge: Harvard University Press, 1985.

. Freedom's Law: The Moral Reading of the American Constitution. Oxford: Oxford University Press, 1996

. Taking Rights Seriously. Cambridge: Harvard University Press, 1978.

ELSTER, Jon. Constitutional Bootstrapping in Philadelphia and Paris. In: ROSENFELD, Michel (Ed.). Constitutionalism, Identity, Difference, and Legitimacy: theoretical perspectives. Durham; London: Duke University Press, 1994.

Deliberation and Constitution Making. In: (Ed.). Deliberative Democracy. Cambridge:

Cambridge University Press, 1999.

. Securities Against Misrule: juries, assemblies, elections. Cambridge: Cambridge University Press, 2013.

ELY, John Hart. Democracia e desconfiança: uma teoria do controle judicial de constitucionalidade. São Paulo: Martins Fontes, 2010.

ESKRIDGE, William. Dynamic Statutory Interpretation. University of Pennsylvania Law Review, v. 135, 1987.

FEREJOHN, John. Judicializing Politics, Politicizing Law. Law and Contemporary Problems, v. 65, n. 3, 2002.

GARGARELLA, Roberto. Full Representation, Deliberation, and Impartiality. In: ELSTER, Jon (Ed.).

Deliberative Democracy. Cambridge: Cambridge University Press, 1999.

GRAY, John Chipman. The Nature and Sources of the Law. New York: Columbia University Press, 1909. 
HABERMAS, Jürgen. Between Facts and Norms: contributions to a discourse theory of law and democracy. Cambridge: MIT Press, 1996.

The inclusion of the other: studies in political theory. Cambridge: MIT Press, 1998

. Three Normative Models of Democracy. Constellations, Oxford, v. 1, n. 1, 1994.

HAMilTON, A.; MADiSON, J.; JAY, J. The Federalist Papers. New York: Signet Classics, 2003.

HART, Herbert L. A. O conceito de direito. Lisboa: Fundação Calouste Gulbenkian, 2007.

HOADLY, Benjamin. The Nature of the Kingdom or Church of Christ. London: James Knapton, 1717.

HOGG, Peter W.; BUSHELL, Allison A. The Charter Dialogue Between Courts and Legislatures (Or Perhaps The Charter of Rights Isn t Such A Bad Thing After All). Osgoode Hall Law Journal, v. 35, 1997.

HOLMES, Stephen. Passions and constraint: on the theory of liberal democracy. Chicago: University of Chicago Press, 1995.

HONIG, Bonnie. Emergency politics: paradox, law, democracy. Princeton: Princeton University Press, 2009.

JENSEN, Merrill. The Articles of Confederation. Madison: University of Wisconsin Press, 1959.

JOHNSON, James. Arguing for Deliberation: Some Skeptical Considerations. In: ELSTER, Jon (Ed.).

Deliberative Democracy. Cambridge: Cambridge University Press, 1999.

KEYSSAR, Alexander. The Right to Vote. New York: Basic Books, 2000.

KOZICKI, Katya. Conflito e estabilização: comprometendo radicalmente a aplicação do direito com a

democracia nas sociedades contemporâneas. 2000. Tese (Doutorado em Direito) - PPGD, UFSC,

Florianópolis, 2000.

LEFORT, Claude. Democracy and Political Theory. Cambridge: Polity, 1988.

. Pensando o político: ensaios sobre democracia, revolução e liberdade. Rio de Janeiro: Paz e Terra, 1991.

. The Permanence of the Theologico-political? In: VRIES, H.; SULLIVAN, L. E. (Eds.). Political

theologies: public religions in a post-secular world. New York: Fordham University Press, 2006.

LORENZETTO, Bruno Meneses. Direito e desconstrução: as aporias do tempo, do direito e da violência. Belo

Horizonte: Arraes Editores, 2013.

LOUGHLIN, Martin. The concept of constituent power. European Journal of Political Theory, v. 13, 2014.

MICHELMAN, Frank I. Brennan and Democracy. Princeton: Princeton University Press, 1999.

NEUHOUSER, Frederick. Freedom, Dependence and the General Will. The Philosophical Review, v. 102, n. $3,1993$.

POST, Robert. Constitutional Domains: Democracy, Community, Management. Cambridge: Harvard University Press, 1995.

ROUSSEAU, Jean-Jacques. The Social Contract \& Discourses. London: J.M. Dent \& Sons, 1923.

SCHAUER, Frederick. Precedent. Stanford Law Review, v. 39, 1987.

SIEYĖS, E. J. A Constituinte burguesa: que é o Terceiro Estado? Rio de Janeiro: Lumen Juris, 1997.

SILVA, Virgílio Afonso da. O STF e o controle de constitucionalidade: deliberação, diálogo e razão pública.

Revista de Direito Administrativo, v. 250, 2009.

SUNSTEIN, Cass. Incompletely Theorized Agreements. Harvard Law Review. v. 108, 1995.

TROPER, Michel. La máquina y la norma: dos modelos de Constitución. Doxa, n. 22, 1999.

TUSHNET, Mark. The Constitution of the United States of America: a contextual analysis. Oxford: Hart, 2009. Why the Constitution Matters. New Have: Yale University Press, 2010.

WHITTINGTON, Kieth E. Judicial Review and Interpretation: have the courts become sovereign when interpreting the Constitution? In: HALL, Kermit L.; MCGUIRE, Kevin T. (Eds.). The Judicial Branch. New York: Oxford University Press, 2005.

Bruno Meneses Lorenzetto

Curitiba - PR - Brasil
bruno_lorenzettolayahoo.com.br
Mestre e Doutor em Direito pela Universidade Federal do

PARANÁ.

Professor da Pontifícia Universidade Católica do Paraná e do Programa de Mestrado em Direito (Direitos

Fundamentals e Democracia) e da Graduação do Centro UnIVERSITÁrIO AUTONNOMO dO BRASIL - UnIBRASIL. 
648 : CONSTITUINDO A CONSTITUIÇÃO: ENTRE PARADOXOS, RAZÕES E RESULTADOS

Katya Kozicki

Curitiba - PR - Brasil

kkozickiluol.com.br
Mestre e doutora em DiREITO PELA Universidade Federal de Santa Catarina.

Professora titular da PontifícIa Universidade Católica do Paraná e professora associada da Universidade Federal do Paraná, nos programas de graduação E Pós-graduação EM DiReITo.

Pesquisadora (bolsista de produtividade EM PESQUISA) DO CNPQ. 